\title{
NEMATODELE PARAZITE - DITYLENCHUS DESTRUCTOR ȘI DITYLENCHUS DIPSACI, ASOCIATE CU TUBERCULI DE CARTOFI DE DIFERITE SOIURI
}

\author{
Melnic Maria, Gliga Olesea \\ Institutul de Zoologie al MECC, or. Chișinău, Republica Moldova \\ E-mail: mariamelnic232@gmail.com
}

https://doi.org/10.53937/9789975315975.49

Nematodele parazite la plantele de cultură, cauzează pagube majore de recoltă la nivel mondial. Conform unor surse, pierderile anuale provocate de fitonematodele parazite constituie 77 miliarde de dolari. Printre cele mai periculoase se enumeră și speciile de nematode din genul Ditylenchus - D. destructor și D.dipsaci. Acestea fiind incluse în lista speciilor de carantină (EU Directive 2000 and/or the EPPO quarantine list). În cercetările multianuale efectuate de noi, cu privire la răspândirea nematodelor parazite la tuberculii de cartofi de diferite soiuri (în total 12 soiuri) - Agata, Albi, Albăstriu mov, Bella rosa, Irga, Desiree, lagodca, Concorde, Kondor, Romano, Roko și Sprinter, colectate în perioada de depozitare, s-a observat, că în majoritatea cazurilor (70\% din totalul gospodăriilor cercetate), în Republica Moldova mai răspândită și mai periculoasă este nematoda tuberculilor $D$. destructor. Ambele specii - $D$. destructor și $D$. dipsaci au fost depistate doar la 3 soiuri (Bella rosa, Roko, Desiree) din cele 12 cercetate.

Menționăm faptul, că a doua specie cercetată de noi - nematoda $D$. dipsaci este una tipică genului Ditylenchus, care spre deosebire de celelalte specii ale acestui gen, printre care și $D$. destructor, include diferite forme, numite rase sau patotipuri biologice, identice după dimensiunile morfologice. Sunt cunoscute circa 20 de rase $D$. dipsaci, care parazitează culturile de secară, ovăs, lucernă, sfeclă, cartof, ceapă, usturoi, căpșun, scăiuș, zambilă, lalele, narciși etc. Rasele biologice $D$. dipsaci se deosebesc mai mult prin preferința plantelor-gazde, de unde provine și denumirea speciei. 
Luând în considerație cele menționate anterior, scopul cercetărilor a fost de a determina susceptibilitatea diferitor soiuri de cartofi către specia $D$. destructor, parazit specific al tuberculilor de cartofi și specia $D$. dipsaci, rasa care parazitează ceapa și usturoiul.

$\mathrm{Au}$ fost efectuate experienţe vegetative de testare a 6 soiuri de cartofi mai răspândite în Republica Moldova: Agata, Romano, Irga, Albăstriu-mov, Kondor, Concorde, pentru a determina susceptibilitatea acestora către speciile de nematode din genul Ditylenchus - D. destructor, care a fost extrasă din cartofi infestaţi în perioada de depozitare și în paralel nematoda $D$. dipsaci, rasa care parazitează cultura usturoiului, care a fost extrasă din bulbi de usturoi infestaţi, colectaţi din depozite.

Tuberculii experimentali de diferite soiuri au fost inoculaţi artificial cu un anumit număr de indivizi maturi - femele (14 indivizi/tubercul) și masculi (11 indivizi/tubercul) ai ambelor specii. Pentru a da posibilitate nematodelor de a se diviza, cartofii inoculați au fost expuși unei incubări pe un termen de $2-2,5$ luni, la temperatura camerei de $14-18^{\circ} \mathrm{C}$, cu susținerea umidității necesare, timp în care pot avea loc ciclurile evolutive ale D. destructor și D. dipsaci.

Rezultatele cercetărilor au demonstrat, că după incubare, toate soiurile de cartofi experimentate au fost infestate cu D. destructor. În tuberculii soiurilor Agata, Romano, Kondor și Concorde, densitatea D. destructor s-a majorat de la 25 indivizi (iniţial inoculaţi) până la 270-380 indivizi/tubercul, după incubare. În suspenziile cercetate au fost observate formele juvenile $-J_{2}, J_{3^{\prime}} J_{4^{\prime}}$ adulţi, precum și ouă ale parazitului, ceea ce denotă, că reproducerea a avut loc. Prin densitatea indivizilor (majoritatea maturi) prezenți, s-au evedențiat soiurile Irga și Albăstriu-mov. După incubare, numărul de nematode din porţiunile inoculate ale acestor tuberculi s-a majorat inițial de la 25 indivizi până la 900 (soiul Irga) și 1350 indivizi (soiul Albăstriu-mov). Menționăm faptul, că nici în unul din tuberculii soiurilor cercetate de cartofi -Agata, Romano, Irga, Albăstriu-mov, Kondor, Concorde, ciclul evolutiv al speciei $D$. dipsaci, rasa care parazitează cea- 
pa și usturoiul, nu s-a produs. Analiza tuberculilor experimentali ai celor 6 soiuri a demonstrat, că densitatea indivizilor D. dipsaci, după inoculare și incubare s-a diminuat de la 25 până la 0, 1, 2 indivizi observați în ţesutul vegetal inoculat.

În opinia noastră specia D.dipsaci, care a fost depistată în cartofii de soi Bella rosa, Roko și Desiree nu este aceeași, care parazitează ceapa și usturoiul, dar ar putea fi o altă rasă a acestei specii. Cercetările sunt în curs de evaluare.

Investigațiile au fost realizate în cadrul proiectului 15.817.02.12 F, finanțat de Consiliul Suprem pentru Știință și Dezvoltare Tehnologică al Academiei de Științe a Moldovei. 